03

\title{
Малогазовая детонация в низкоплотных механоактивированных порошковых смесях
}

\author{
() С.А. Рашковский, ${ }^{1,3}$ А.Ю. Долгобородов ${ }^{2,3,4}$ \\ ${ }^{1}$ Институт проблем механики им. А.Ю. Ишлинского РАН, \\ 119526 Москва, Россия \\ ${ }^{2}$ Объединенный институт высоких температур РАН, \\ 125412 Москва, Россия \\ ${ }^{3}$ Институт химической фризики им. Н.Н. Семенова РАН, \\ 119991 Москва, Россия \\ ${ }^{4}$ НИЯУ МИФИ, \\ 115409 Москва, Россия \\ e-mail: rash@ipmnet.ru
}

Поступило в Редакцию 4 апреля 2017 г.

В окончательной редакции 11 февраля 2018 г.

Принято к публикации 27 декабря 2018 г.

\begin{abstract}
Проведен анализ экспериментальных данных по сверхзвуковому самоподдерживающемуся распространению волны энерговыделения в низкоплотных механоактивированных смесях. Проанализированы различные механизмы, которые могут быть ответственны за этот процесс, и предложен механизм детонационноподобного распространения реакции в порошковых смесях. Показано, что при определенных условиях этот процесс обладает всеми признаками детонации и должен быть признан одной из разновидностей детонации. Показано, что этот вид детонации принципиально отличается от классической „идеальной“ детонации, например, в газах: вместо ударной волны по порошковой смеси распространяется волна уплотнения, в которой происходит в основном не сжатие материала частиц, а уплотнение порошка за счет взаимного перемещения частиц. При этом инициирование химической реакции происходит за счет взаимного трения частиц окислителя и горючего в волне уплотнения порошка.
\end{abstract}

DOI: 10.21883/JTF.2019.06.47627.2283

\section{Введение}

Детонацией (в обобщенном смысле) может быть назван любой самоподдерживающийся процесс энерговыделения, распространяющийся в реакционноспособной среде со скоростью, превышающей скорость звука в исходном веществе, если волна сжатия, которую создает расширяющееся в зоне энерговыделения вещество, обеспечивает выделение энергии в количестве и со скоростью, достаточной для поддержания ее дальнейшего распространения, т.е. компенсирующей естественное затухание волны сжатия. Расширяющееся в зоне энерговыделения вещество играет роль поршня, толкающего перед собой волну сжатия.

Детонация в разных по своей структуре, реологии и химическому составу веществах может отличаться механизмом инициирования и физической природой энерговыделения на фронте или за фронтом ударной волны. Примерами могут служить:

I) классическая детонация в сплошных средах (жидкостях, газах, твердых телах), имеющих газообразные продукты сгорания, при этом адиабатическое сжатие среды в ударной волне инициирует экзотермические химические реакции и создает условия для их быстрого протекания за ее фронтом;

II) детонация в гетерогенных пористых ВВ по баллистическому механизму, когда впереди волны сжатия распространяются высокоскоростные струи горячих продуктов [1];

III) светодетонационная волна [2], при которой энерговыделение за фронтом ударной волны вызвано поглощением мощного лазерного излучения в сжатой среде, при этом сжатие среды происходит в обычной ударной волне, а изменение плотности среды и, главным образом, ее ионизация за ударной волной резко повышают коэффициент поглощения лазерного излучения по сравнению с исходной средой;

IV) твердофазная детонация без промежуточных газообразных продуктов (безгазовая детонация) - гипотетический процесс, который в настоящее время в чистом виде экспериментально не реализован, но теоретически принципиально возможен [3-7].

В истинно безгазовой детонации роль поршня, сжимающего исходное вещество, играют конденсированные продукты реакции, которые для этого должны быстро и существенно увеличиваться в объеме либо за счет теплового расширения, либо за счет образования менее плотных, чем исходное вещество, конденсированных продуктов синтеза.

Процессы, близкие к безгазовой детонации, реализованы в низкоплотных механоактивированных порошковых смесях [8-13]. В этих экспериментах роль поршня, уплотняющего исходный порошок, играют газообразные продукты сгорания частиц, при этом в ряде случаев га- 
зообразными являются только промежуточные продукты сгорания, в то время как исходные частицы и конечные продукты реакции находятся в твердом состоянии.

Отметим, что скорость звука в низкоплотном порошке, как „сплошной среде“, составляет $100-300 \mathrm{~m} / \mathrm{s} \quad[9,14,15]$, поэтому любая волна энерговыделения, движущаяся относительно исходного порошка со скоростью более $300 \mathrm{~m} / \mathrm{s}$, будет сверхзвуковой. Очевидно, не любая сверхзвуковая волна энерговыделения может быть названа детонационной волной. Для того чтобы волна энерговыделения, движущаяся со сверхзвуковой скоростью в порошковой смеси, могла считаться детонационной волной, она должна создавать перед собой волну уплотнения порошка или ударную волну в газе, заполняющем поры, которые непосредственно инициируют реакцию в частицах порошка. Для того чтобы волна уплотнения порошка могла непосредственно инициировать и ускорять химические реакции в частицах, она должна быть достаточно сильной. Для этого в ней должно происходить существенное повышение плотности порошка, что подразумевает высокое давление в порошке и в газообразных продуктах сгорания частиц за фронтом волны уплотнения. Кроме того, порошковая смесь должна обладать высокой химической активностью, чтобы волна уплотнения могла инициировать в ней химические реакции, и эти реакции протекали с достаточно высокой скоростью, необходимой для поддержания волны уплотнения.

Для повышения скорости энерговыделения в смесях металлов с твердыми окислителями в работах [8-13] использовалась предварительная механическая активация порошков. Было показано, что механоактивация смесей $\mathrm{Me} / \mathrm{X}\left(\mathrm{Me}=\mathrm{Mg}, \mathrm{Al}, \mathrm{Si} ; \mathrm{X}=\mathrm{MoO}_{3}\right.$, фторопласт $\left.\left(-\mathrm{CF}_{2}-\mathrm{CF}_{2}\right)_{n}\right)$, перхлорат калия $\mathrm{KClO}_{4}($ ПХК), перхлорат аммония $\mathrm{NH}_{4} \mathrm{ClO}_{4}$ (ПХА), нитрат калия $\mathrm{KNO}_{3}$ (НК) увеличивает их скорость горения на три порядка и способствует переходу горения в детонацию.

Так, например, для смеси нанопорошка кремния (средний размер $\sim 60 \mathrm{~nm})$ с перхлоратом аммония (nSi/ПXА) были получены уникально высокие скорости взрывного горения $\sim 600 \mathrm{~m} / \mathrm{s}$ и наблюдался переход горения в детонацию в пористых образцах. При пористости исходной смеси 70-80\% переход горения в детонацию происходил на длине 20-60 mm, при этом достигались скорости детонации $1300-2000 \mathrm{~m} / \mathrm{s}$. При увеличении размеров наночастиц кремния (свыше $150 \mathrm{~nm}$ ) или уменьшении доли активного кремния в порошке наблюдались относительно невысокие скорости горения $(100-130 \mathrm{~m} / \mathrm{s})$ без перехода в детонацию.

Для насыпных зарядов Al/ПХК (пористость 70-80\%) на основе алюминиевой пиротехнической пудры ПП-2 в стальных трубках диаметром $10 \mathrm{~mm}$ длина перехода в детонацию составляла от 1 до $7 \mathrm{~cm}$, а скорость детонации была 1000-1500 m/s (в отдельных экспериментах до $2400 \mathrm{~m} / \mathrm{s}$ с длиной перехода $1-2 \mathrm{~cm})$. Установлено, что длина перехода в детонацию и скорость стационарной детонации зависят от состава смесей и времени активации [8-13]. Так, при времени активации $2 \mathrm{~min}$ переход в детонацию не наблюдался, а регистрировалось взрывное горение со скоростью $420 \mathrm{~m} / \mathrm{s}$, при этом трубка сохранялась без значительных разрушений. При времени активации более $5 \mathrm{~min}$ наблюдался переход горения в детонацию. При этом максимальные скорости были получены для смесей Al/ПХК 30/70. При времени активации более $40 \mathrm{~min}$ происходило снижение скорости, что свидетельствует о частичном реагировании компонентов в процессе механообработки.

В механоактивированных смесях Al/фторопласт (пористость 70-80\%) наблюдалась стационарная детонация со скоростями 700-1300 m/s в зависимости от содержания алюминия в смеси. Давление в продуктах детонации оценивалось по измерениям давления ударной волны в пластинах из фторопласта или алюминия, расположенных в конце заряда, которое составляло 0.5-1.6 GPa, что соответствует давлению в продуктах $0.1-0.3 \mathrm{GPa}$.

Эксперименты [8-13] показывают, что при пористости порошка ниже некоторого предела $(\sim 60 \%)$ детонация в исследованных смесях не наблюдается: происходит только относительно медленное горение со скоростями от нескольких десятков до нескольких сотен метров в секунду без перехода в детонацию. Из экспериментов [813] следует, что начальная плотность порошка играет в этом процессе принципиальную роль, которая до конца не выяснена.

\section{Механизмы передачи теплового импульса}

Экспериментальные данные [8-13] позволяют сделать вывод, что безгазовая детонация (как истинная, так и „малогазовая“) может быть получена в низкоплотных порошковых смесях (пористость более 60\%) с высокой химической активностью частиц, которая достигается как за счет увеличения контактной поверхности окислитель-горючее в хорошо перемешанных наноразмерных смесях, так и за счет предварительной механоактивации.

Теоретически пористость порошка может влиять на скорость распространения фронта энерговыделения либо через фильтрацию горячих продуктов сгорания, которые могут поджигать еще не воспламенившиеся частицы перед детонационным фронтом (фронтом горения), либо через сжатие порошка под действием давления газообразных продуктов горения.

Очевидно, чем меньше начальная плотность порошка, тем больше возможная степень его уплотнения. Уплотнение порошка при сверхзвуковом распространении энерговыделения происходит в виде волны уплотнения, в которой относительная плотность порошка может изменяться в 2-3 раза. Расширяющиеся газообразные продукты сгорания частиц играют роль поршня, который уплотняет впереди лежащий слой порошка. Контактирующие частицы передают сжимающее усилие следующим 
слоям порошка, что и формирует волну уплотнения относительно узкую зону с переменной по ширине плотностью порошка. Такая волна уплотнения может распространяться по исходному порошку с почти постоянной скоростью, превышающей скорость звука в исходном порошке $[14,15]$. Волна уплотнения в порошке является аналогом ударной волны в газах. Эта аналогия становится еще более наглядной, если учесть, что ширина ударной волны в газе порядка нескольких длин свободного пробега молекул, а ширина волны (зоны) уплотнения в низкоплотных порошках порядка нескольких средних размеров пор между частицами $[14,15]$ (средний размер пор является своеобразной ,длиной свободного пробега“ частиц в порошке).

При адиабатическом сжатии газа в ударной волне его нагрев происходит за счет перехода механической энергии газового потока в тепловую энергию. В этом заключается механизм передачи теплового импульса в детонационной волне в газах (а также в жидкостях и сплошных твердых телах). В отличие от газов механизм передачи теплового импульса от горящих частиц к еще не воспламенившимся при „безгазовой“ детонации низкоплотной порошковой смеси остается неясным.

Основными кандидатами на роль такого механизма являются:

1. Кондуктивный механизм, при котором тепло передается от частицы к частице через их контакты (контактная теплопроводность). Как показано в [16,17], скорость горения механоактивированных порошков при чисто контактной теплопроводности между частицами уменьшается с ростом пористости порошковой смеси, что противоречит данным работ [8-13]. Это означает, что кондуктивный механизм не может играть основной роли в процессе быстрого горения и тем более детонации низкоплотных порошковых смесей.

2. Конвективный механизм (ударная фильтрация), при котором горячие газообразные продукты сгорания фильтруются через поры и поджигают еще не воспламенившиеся частицы. Очевидно, этот механизм возможен только в случае, когда имеются либо конечные, либо промежуточные газообразные продукты сгорания; в истинно безгазовой детонации этот механизм не реализуется. По нашему мнению, конвективный механизм может играть роль только при взрывном горении низкоплотных порошковых смесей, исследованных в [8-13], обеспечивая аномально высокие скорости горения (до $600 \mathrm{~m} / \mathrm{s}$ ), а также при переходе горения в детонацию, обеспечивая на начальной стадии ускорение процесса и повышение давления в продуктах сгорания до значений, при которых в действие вступают другие, более быстрые механизмы передачи теплового импульса. При детонации низкоплотной порошковой смеси конвективный механизм передачи теплового импульса оказывается слишком медленным: простые оценки показывают, что при скорости детонации $\sim 1000 \mathrm{~m} / \mathrm{s}$ нагрев частиц за счет фильтрации горячих газообразных продуктов сго- рания за время прохождения детонационного фронта по частице не превышает нескольких десятков градусов.

3. Струйный (эстафетный) механизм, при котором горящие частицы „разбрасывают“ вокруг себя раскаленные фрагменты (капли) и струи. Попадая на еще не воспламенившиеся частицы, находящиеся в пределах „прямой видимости“, они могут их поджечь, что обеспечит передачу теплового импульса следующим слоям порошковой смеси. Этот механизм является разновидностью эстафетного механизма. Очевидно, для того чтобы такой процесс определял скорость детонации, струи и фрагменты горящих частиц должны иметь скорость существенно большую, чем наблюдаемая в экспериментах скорость детонации (т.е. несколько $\mathrm{km} / \mathrm{s}$ ). Отметим, что роль пористости в этом процессе неоднозначна: с одной стороны, высокая пористость способствует образованию и распространению горячих фрагментов и струй, но с другой стороны, чем выше пористость порошка, тем больше (в среднем) времени требуется для их пролета через поры, и тем меньше будет объемное энерговыделение. Это означает, что скорость передачи теплового импульса по этому механизму должна падать с увеличением пористости порошка, что противоречит наблюдениям [8-13].

4. Ударное инициирование химических реакций [3-7], при котором высокие напряжения и деформации, возникающие в частицах при быстром (ударном) уплотнении порошка, инициируют быстрые экзотермические реакции на поверхности контакта частиц горючего и окислителя. Чем выше пористость исходного порошка, тем большие относительные скорости могут приобрести частицы в волне уплотнения. Таким образом, повышение пористости порошка должно способствовать ударному инициированию, что согласуется с экспериментальными данными [8-13].

5. Нагрев частии окислителя и горючего (преимущественно в зоне их контакта) за счет трения при быстром сжатии порошка в волне уплотнения [18]. При уплотнении порошка возникает трение как между контактирующими частицами, так и между частицами и стенками трубы, в которой находится порошок. Чем выше пористость порошка, тем большие относительные перемещения совершают частицы в волне уплотнения, тем большую работу совершают силы трения, и, следовательно, тем большую температуру приобретут трущиеся частицы. В работе [13] показано, что механоактивированные нанокомпозиты $\mathrm{nSi} / \Pi \mathrm{XA}, \mathrm{nSi} / \Pi \mathrm{XK}, \mathrm{Al} / \mathrm{MoO}_{3}$ и $\mathrm{Mg} / \mathrm{MoO}_{3}$ имеют очень высокую чувствительность к трению, сопоставимую с чувствительностью азида свинца. Данные работы [13] указывают на определенную корреляцию между чувствительностью механоактивированных композитов к трению и их скоростью детонации. Так, нанокомпозиты nSi/ПХА имеют более высокую чувствительность к трению и одновременно более высокую скорость детонации по сравнению с нанокомпозитами $\mathrm{nSi} /$ ПХК; в то же время нанокомпозиты $\mathrm{nSi} / \mathrm{HK}$ имеют примерно в 20 раз меньшую чувствительность к трению, 
чем азид свинца, и для них не удалось инициировать детонацию - наблюдалось только быстрое горение со скоростью $590 \mathrm{~m} / \mathrm{s}$. По отпечаткам на пластинахсвидетелях было обнаружено существенно неравномерное воздействие продуктов детонации на поверхность пластины. Наибольшее воздействие (как механическое, так и эрозионное) наблюдается на периферии пластины, что свидетельствует о неравномерном детонационном фронте: скорость детонации и соответственно скорость продуктов детонации на периферии (у стенки трубы) выше, чем в ее центральной части. Это можно объяснить более высоким трением между частицами порошка и стенками трубы, чем между контактирующими частицами порошка, что приводит к более быстрому нагреву частиц при сжатии порошка в волне уплотнения у стенок трубы по сравнению с центральной областью. Результатом являются более высокие скорость детонации и давление детонации у стенок трубы. Эта картина полностью противоположна той, что наблюдается при детонации газовой смеси в трубе: скорость детонации у стенок трубы всегда меньше, чем в ее центральной части, что связано с вязкостью газа и с тепловыми потерями в стенку.

Можно ожидать, что все вышеперечисленные механизмы в той или иной степени участвуют в передаче теплового импульса от горящих частиц к еще не воспламенившимся при детонации низкоплотных порошковых смесей и, в особенности, при переходе горения в детонацию. Однако среди этих механизмов можно выделить основной, отвечающий за закономерности рассматриваемого процесса, в то время как остальные механизмы являются второстепенными.

В большинстве работ по безгазовой детонации за основу принят ударный механизм инициирования химических реакций [3-7]. Однако, как показывают оценки [3-7], он требует очень высоких давлений (десятки $\mathrm{GPa}$ ), которые не реализуются при детонации низкоплотных механоактивированных порошковых смесей $[8-13]$.

Проведенный выше анализ показывает, что более вероятным механизмом инициирования частиц при „безгазовой“" детонации в низкоплотных порошковых смесях является трение между контактирующими частицами окислителя и горючего, а также между частицами и стенками трубки, в которую запрессовывается порошковая смесь.

Для описания безгазовой детонации обычно используется традиционный гидродинамический подход, результатом которого является обычная адиабата Гюгонио [3-7]. Такой подход обоснован только в случае, если нагрев среды в волне уплотнения порошковой смеси связан с адиабатическим сжатием материала частиц, как сплошной среды. Это имеет место только для очень плотных порошков, относительная плотность которых близка к единице. Если относительная плотность порошка существенно меньше единицы, то его уплотнение является сложным многостадийным процессом [19].
Обычно выделяют три стадии уплотнения порошка: (i) низкая относительная плотность (менее 0.5); уплотнение порошка происходит за счет перегруппировки частиц в пространстве в результате их взаимного перемещения без заметной деформации частиц и без их разрушения; сопротивление сжатию порошка на этой стадии связано с взаимным трением частиц и с их инерционностью. (ii) средняя относительная плотность (0.5-0.7); уплотнение порошка происходит за счет разрушения (фрагментации) частиц и перегруппировки их фрагментов в пространстве в результате взаимного перемещения. (iii) высокая относительная плотность (более 0.7); уплотнение порошка происходит за счет пластической деформации частиц и их фрагментов.

Так как ширина волны уплотнения порошка есть величина порядка нескольких средних размеров пор, можно оценить время пребывания частиц порошка в волне уплотнения (до момента их воспламенения) по формуле $\tau \sim k\left(\frac{1}{\rho-1}\right)^{1 / 3} \frac{d}{D}$, где $d-$ размер частиц, $\rho$ - относительная плотность исходного порошка, $D-$ скорость волны, $k<10$. Например, для $d \sim 1 \mu \mathrm{m}, D=1000 \mathrm{~m} / \mathrm{s}$, $\rho=0.3$ и $k=10$ получим $\tau \sim 0.1 \mu \mathrm{s}$. За столь короткое время частицы порошка не успевают заметно деформироваться, поэтому можно ожидать, что в волне уплотнения реализуется только первая стадия уплотнения порошка.

\section{Модель „безгазовой“ детонации}

Рассмотрим одномерную модель волны уплотнения в порошковой смеси окислителя и горючего, реагирующих с образованием конечных твердых веществ при наличии промежуточных газообразных продуктов.

В отличие от ударных волн в газах волну уплотнения в порошке следует рассматривать не как геометрическую поверхность, на которой происходит скачок параметров, а как зону конечной (хотя и малой) толщины, в которой происходит непрерывное изменение плотности порошковой смеси, давления в порошке и температуры частиц. При этом следует различать давление в порошке и давление в газе, заполняющем поры между частицами.

Рассмотрим случай, когда ролью газа, заполняющего поры между частицами в исходном порошке, можно пренебречь. Более того, считается, что газообразные продукты сгорания также не принимают непосредственного участия в нагреве и воспламенении частиц порошка; они играют только роль поршня, уплотняющего порошок.

Уравнения одномерного движения порошка, как сжимаемой среды, имеют обычный вид

$$
\begin{gathered}
\frac{\partial \rho}{\partial t}+\frac{\partial \rho v}{\partial x}=0, \\
\frac{\partial \rho v}{\partial t}+\frac{\partial \rho v^{2}}{\partial x}=-\frac{1}{\gamma} \frac{\partial \sigma}{\partial x},
\end{gathered}
$$

где $\gamma$ - плотность материала частиц порошка, $\rho$ - относительная плотность порошка, $v$ - скорость порошка, 
как сплошной среды, $\sigma$ - давление (напряжение сжатия) в порошке, как сплошной среде. По определению

$$
\sigma=\frac{R}{F}
$$

где $R$ - сила, действующая между частями порошка, разделенными поперечным сечением, имеющим площадь $F$. Напряжение $\sigma$ является давлением внутри порошка, вызванным взаимным действием частиц.

Уравнения (1) и (2) должны быть дополнены реологическим уравнением, описывающим связь давления в порошке с его плотностью и скоростью уплотнения (скоростью изменения плотности).

Рассмотрим стационарную волну уплотнения, движущуюся относительно исходного (неуплотненного) порошка со скоростью $D$. Как обычно, будем использовать систему отсчета, движущуюся вместе с волной уплотнения (систему покоя волны уплотнения). Ось $x$ направим в сторону исходного порошка (в направлении движения волны уплотнения). В этой системе отсчета исходный порошок будет двигаться со скоростью $-D$, а параметры порошка не будут зависеть от времени. Тогда уравнения (1), (2) принимают вид

$$
\begin{gathered}
\frac{d \rho v}{d x}=0 \\
\frac{d \rho v^{2}}{d x}=-\frac{1}{\gamma} \frac{d \sigma}{d x} .
\end{gathered}
$$

Уравнения (4) и (5) с учетом естественных граничных условий (при $x=\infty$ ) имеют решения

$$
\begin{gathered}
\rho v=-\rho_{0} D, \\
\gamma \rho v^{2}+\sigma=\gamma \rho_{0} D^{2},
\end{gathered}
$$

где $\rho_{0}$ - относительная плотность исходного порошка. Здесь считается, что в исходном (несжатом) порошке давление равно нулю:

$$
\sigma(\infty)=0
$$

Используя (6), запишем (7) в виде

$$
\sigma=\gamma \rho_{0} D^{2}\left[1-\frac{\rho_{0}}{\rho}\right] .
$$

Это соотношение, известное, как прямая Михельсона (или прямая Рэлея), устанавливает связь между давлением и плотностью порошка в волне уплотнения.

В отличие от сплошных сред (газов, жидкостей, твердых тел), в которых сжатие связано с преодолением теплового движения атомов и молекул и сил взаимодействия между ними и является обратимым, в порошках уплотнение (по крайней мере, на первой стадии) связано с взаимным перемещением твердых частиц, а следовательно, с трением между частицами. По этой причине уплотнение порошка является необратимым процессом, а работа, совершаемая при уплотнении порошка, является, главным образом, работой сил трения между контактирующими частицами.

Работа сил давления при уплотнении порошка в расчете на единицу массы порошка

$$
A=-\frac{1}{\gamma} \int_{\rho_{0}}^{\rho} \sigma d \frac{1}{\rho} .
$$

Здесь рассматривается уплотнение порошка от начальной плотности $\rho_{0}$ до некоторой плотности $\rho>\rho_{0}$.

Так как уплотнение порошка в волне уплотнения происходит быстро (адиабатически), с достаточной точностью можно считать, что на первой стадии уплотнения порошка силы трения приводят к нагреву частиц порошка, при этом вся работа сил трения (10) переходит в тепло: $\Delta Q=A$, где $\Delta Q-$ тепло, выделившееся при трении между частицами.

Это позволяет оценить изменение температуры частиц порошка при его уплотнении

$$
\gamma c_{p} \Delta T=\beta \int_{\rho_{0}}^{\rho} \frac{\sigma}{\rho^{2}} d \rho,
$$

где $c_{p}$ - удельная теплоемкость порошка, $\beta$ - коэффициент, в среднем учитывающий неоднородное трение в порошке и неравномерный нагрев частиц порошка.

С учетом (9) получим

$$
c_{p} \Delta T=\frac{1}{2} \beta D^{2}\left(1-\frac{\rho_{0}}{\rho}\right)^{2} .
$$

Отметим, что соотношение (12) заменяет уравнение Ренкина-Гюгонио, используемое в гидродинамической теории детонации сплошных сред.

Здесь предполагается, что все тепло (10), выделившееся при трении частиц в процессе уплотнения порошка, равномерно распределяется между частицами порошка и при этом считается, что частицы порошка нагреваются равномерно. В действительности разные частицы порошка находятся в разных условиях, что связано со случайной структурой порошка. Это приводит к тому, что среднее количество тепла (10), выделившееся при уплотнении порошка, неравномерно распределено между частицами: некоторые частицы получат больше тепла, а некоторые соответственно меньше. Кроме того, частицы порошка нагреваются неравномерно по своему объему, и эта неравномерность тем выше, чем меньше коэффициент теплопроводности материала частиц. Точный учет этих факторов возможен только в рамках статистического подхода, аналогичного кинетической теории газов, либо при прямом численном моделировании уплотнения порошка, когда производится детальный расчет движения каждой частицы с учетом ее механического, теплового и химического взаимодействий с другими частицами. Такой подход нам представляется 
наиболее перспективным и будет описан в следующих работах.

В настоящей работе будем пренебрегать неравномерностью выделения тепла при трении разных частиц, и будем считать, что теплопроводность частиц настолько велика, что выделившееся при трении тепло равномерно распределяется по объему частиц.

Будем считать, что при достижении некоторой температуры $T_{i g n}$ происходит воспламенение частицы. Температуру воспламенения $T_{i g n}$ будем считать постоянной и заданной характеристикой порошка. Отметим, что в более последовательной модели вместо температуры воспламенения можно использовать, например, аррениусовскую кинетику химических реакций в частицах порошка. Тогда воспламенение частицы будет представлять собой тепловой взрыв, который инициируется трением между частицами.

Рассматриваемый подход позволяет оценить степень уплотнения порошка в волне уплотнения, при которой происходит воспламенение его частиц:

$$
c_{p} \Delta T_{i g n}=\frac{1}{2} \beta D^{2}\left(1-\frac{\rho_{0}}{\rho_{i g n}}\right)^{2},
$$

где $\Delta T_{i g n}=T_{i g n}-T_{0}, T_{0}-$ начальная температура порошка, $\rho_{i g n}-$ плотность, при которой достигается температура $T_{i g n}$ в процессе уплотнения порошка.

В сечении порошка, в котором достигается условие (13), начинается горение на поверхности контакта частиц горючего и окислителя с образованием промежуточных газообразных продуктов, что приводит к резкому повышению давления. Это сечение будем называть фронтом детонации в низкоплотной порошковой смеси. Для координаты фронта детонации в подвижной системе координат примем $x=0$. Считается, что до фронта детонации $(x>0)$ газовая фаза отсутствует и имеется только порошок, в то время как за фронтом детонации $(x<0)$ присутствует двухфазная смесь: газообразные продукты горения частиц и сами горящие частицы порошка. Частицы порошка за фронтом детонации не контактируют, так как отталкиваются друг от друга газообразными продуктами сгорания, оттекающими от их поверхности.

Газообразные продукты сгорания за фронтом детонации создают давление на слой порошка, лежащий непосредственно перед фронтом детонации. Именно это давление, передаваемое другим слоям частиц, находящимся перед фронтом детонации, является причиной уплотнения порошка. Можно ожидать, что давление в порошке на фронте детонации $\sigma(0)$ будет пропорционально давлению $p$ в газообразных продуктах сгорания непосредственно за фронтом детонации

$$
\sigma(0)=\eta \rho_{i g n} p
$$

где коэффициент $\eta$ может слабо зависеть от $\rho_{i g n}$. В этой работе он считается постоянным. Зависимость $\rho(0)$ от $\rho_{i g n}$ учитывает тот факт, что, чем плотнее слой частиц на фронте детонации, тем с большей силой газообразные продукты горения давят на невоспламенившийся порошок.

Учитывая (9), получим

$$
\eta \rho_{i g n} p=\gamma \rho_{0} D^{2}\left[1-\frac{\rho_{0}}{\rho_{i g n}}\right] .
$$

Введем степень уплотнения порошка на фронте детонации

$$
\xi_{i g n}=\frac{\rho_{i g n}}{\rho_{0}} .
$$

Тогда из уравнений (13), (15) получим

$$
p=p_{0}\left(\xi_{i g n}-1\right)^{-1}
$$

и

$$
D=D_{0} \frac{\xi_{i g n}}{\xi_{i g n}-1} .
$$

Отсюда найдем

$$
\xi_{i g n}=1+\frac{1}{\pi}
$$

и

$$
D=D_{0}(\pi+1)
$$

где

$$
\pi=p / p_{0}
$$

— безразмерное давление газов на фронте детонации,

$$
p_{0}=\frac{2 \gamma c_{p} \Delta T_{i g n}}{\beta \eta}
$$

— характерное давление детонации,

$$
D_{0}=\left(\eta p_{0} / \gamma\right)^{1 / 2}
$$

- характерная скорость детонации. С учетом получим

$$
D_{0}=\left(2 c_{p} \Delta T_{i g n} / \beta\right)^{1 / 2} \text {. }
$$

Соотношения (19) и (20) устанавливают связь степени уплотнения порошка на фронте детонации и скорости детонации с давлением газообразных продуктов сгорания за фронтом детонации. Отметим линейную зависимость скорости „безгазовой“6 детонации от давления за фронтом детонации.

На рис. 1 приведена зависимость степени уплотнения порошка в волне детонации от безразмерного давления за фронтом детонационной волны. Из формулы (19) и рис. 1 следует, что степень уплотнения порошка в волне детонации уменьшается с ростом давления за фронтом детонационной волны, и при очень большом давлении $p_{0} \gg 1$ степень уплотнения порошка стремится к единице. Этот на первый взгляд странный результат имеет простое объяснение: с ростом давления растет (по линейному закону) скорость детонации. В результате время пребывания порошка в волне уплотнения (до момента воспламенения частиц) уменьшается с ростом давления, а вместе с ним уменьшается и степень сжатия порошка, не успевающего достичь больших плотностей. 


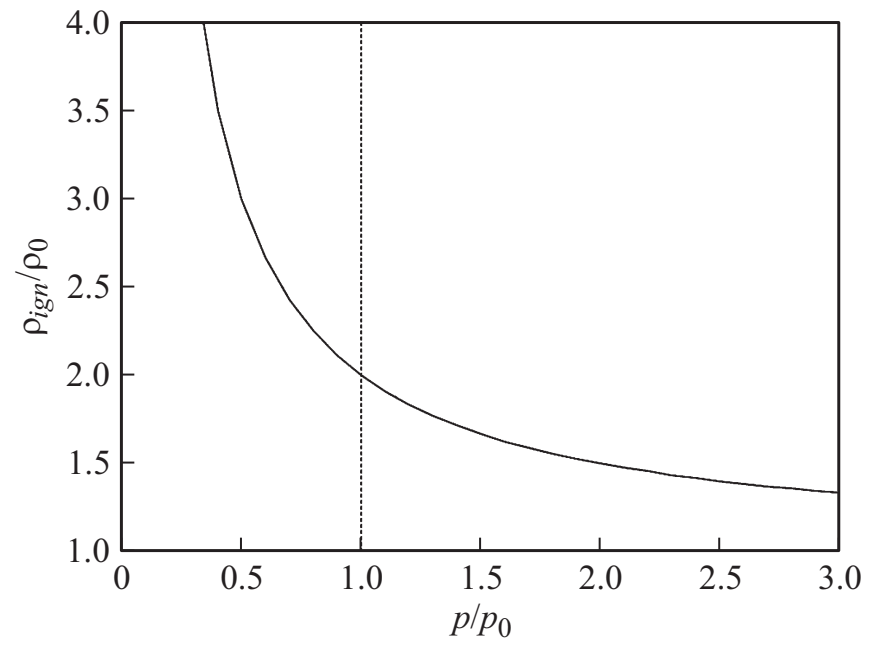

Рис. 1. Зависимость степени уплотнения порошка в волне детонации от безразмерного давления за фронтом детонационной волны. Вертикальная штриховая линия соответствует $p=p_{0}$.

Относительная плотность порошка, которая может быть достигнута только за счет перегруппировки частиц без их деформации и разрушения, не превышает некоторого значения $\rho_{\max }$. Обычно $\rho_{\max } \approx 0.5$. Поэтому полученные выше результаты справедливы до тех пор, пока $\rho_{i g n}<\rho_{\max }$. Отметим интересный факт: до этого момента мы не использовали никакой реологический закон, описывающий поведение порошковой среды, а значит полученные выше результаты не зависят от конкретного вида реологического закона.

Соотношения (20), (21) и (23) позволяют оценить характерное давление $p_{0}$ по значениям скорости детонации и давления за фронтом детонации, измеренным в эксперименте.

Подставляя (21) и (23) в соотношение (20), получим квадратное уравнение относительно $p_{0}$ при известных $p$ и $D$. Это уравнение имеет два решения

$$
p_{0}=z^{2}
$$

где

$$
z_{1,2}=\frac{1}{2}(\gamma / \eta)^{1 / 2} D \pm \sqrt{\frac{\gamma D^{2}}{4 \eta}-p} .
$$

Отметим, что

$$
z_{1} z_{2}=p
$$

Самым неопределенным параметром в этом выражении является коэффициент $\eta$, который должен удовлетворять условию

$$
\eta \leq \frac{\gamma D^{2}}{4 p}
$$

Согласно данным работ [8-10], в экспериментах с механоактивированной смесью $\mathrm{Al} /$ фторопласт были получены значения $D=700 \ldots 1300 \mathrm{~m} / \mathrm{s}$ и $p=0.5 \ldots 1.6 \mathrm{GPa}$. На рис. 2 приведены зависимости $p_{0} / p$ от параметра $\eta$ для разных сочетаний экспериментальных значений
$(D, p)$, соответствующих экспериментам [8-10]. В расчетах принято $\gamma=2000 \mathrm{~kg} / \mathrm{m}^{3}$. Верхняя ветвь на этом графике соответствует решению (26) со знаком „+““, нижняя - решению (26) со знаком „-““. Таким образом, при одном и том же значении параметра $\eta$ заданному сочетанию экспериментальных значений $(D, p)$ могут соответствовать два разных характерных давления детонации $p_{0}$ : одно больше наблюдаемого в эксперименте давления $p$, другое - меньше. Используя формулу (22), можно оценить температуру воспламенения частиц в волне детонации, которая может быть достигнута за счет трения между частицами при уплотнении порошка

$$
\Delta T_{i g n}=\frac{\beta \eta p_{0}}{2 \gamma c_{p}}
$$

На рис. 3 представлены зависимости $\Delta T_{i g n}$ от параметра $\eta$ для тех же сочетаний экспериментальных значений $(D, p)$. В расчетах принято $\gamma=2000 \mathrm{~kg} / \mathrm{m}^{3}$; $c_{p}=1 \mathrm{~kJ} /(\mathrm{kg} \cdot \mathrm{K}) ; \beta=1$.

Как и давление $p_{0}$, температура воспламенения $\Delta T_{i g n}$, которая может быть достигнута за счет трения между частицами в волне уплотнения порошка, имеет два разных значения при одном и том же значении параметра $\eta$. Верхняя ветвь кривых на рис. 3 (как и на рис. 2) соответствует решению (26) со знаком „,+“, нижняя решению (26) со знаком „--“. Видно, что детонационная волна, соответствующая решению со знаком „-“, возможна только при нереально низкой температуре воспламенения частиц порошка. Отсюда приходим к выводу, что рассматриваемому виду детонации в низкоплотной порошковой смеси может соответствовать

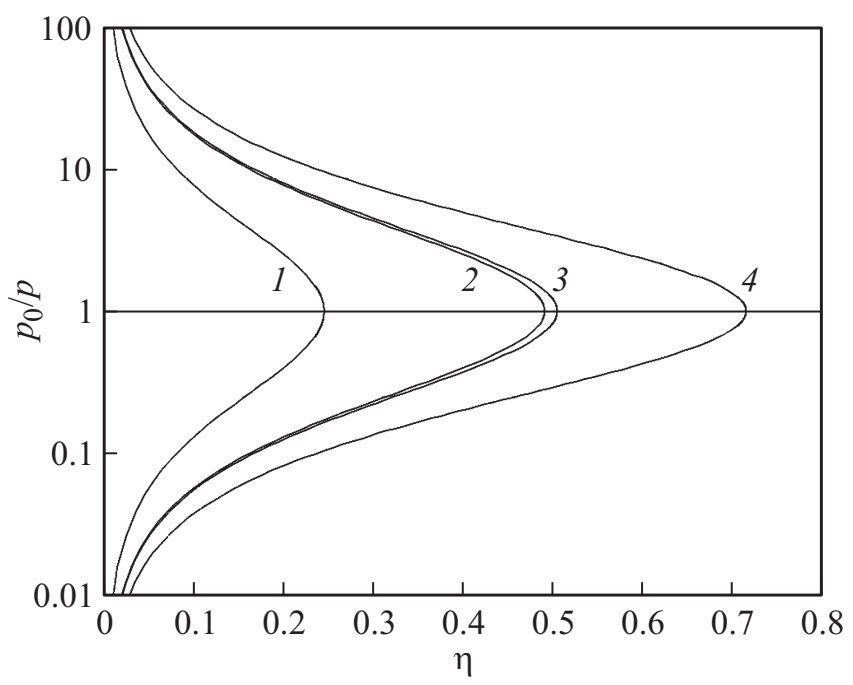

Рис. 2. Зависимости $p_{0} / p$ от параметра $\eta$ для разных сочетаний экспериментальных значений $(D, p)$, соответствующих экспериментам [8-10]: $1-D=700 \mathrm{~m} / \mathrm{s}, \quad p=1 \mathrm{GPa}$; $2-D=700 \mathrm{~m} / \mathrm{s}, p=0.5 \mathrm{GPa} ; 3-D=1100 \mathrm{~m} / \mathrm{s}, p=1.2 \mathrm{GPa}$; $4-D=1000 \mathrm{~m} / \mathrm{s}, p=0.7 \mathrm{GPa}$. 


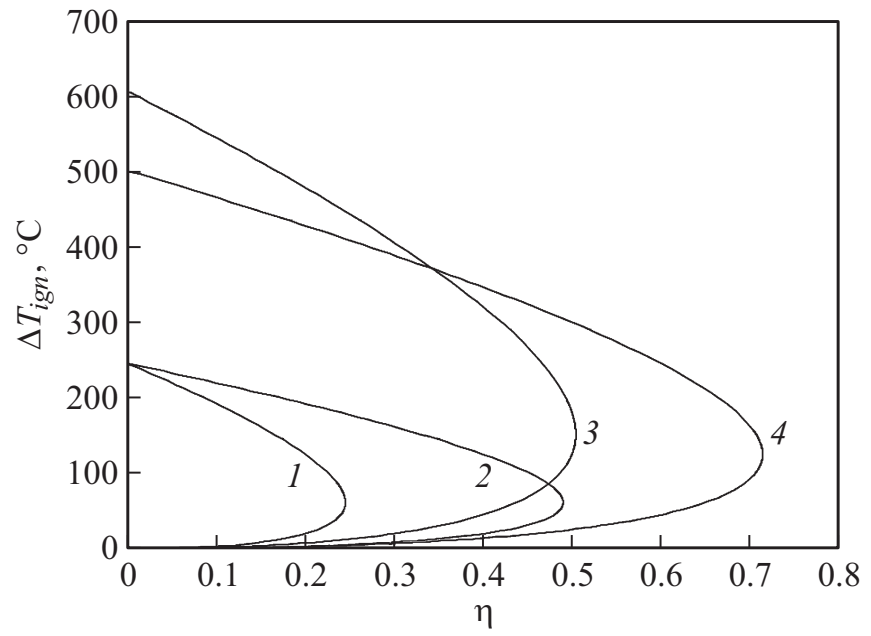

Рис. 3. Зависимости $\Delta T_{i g n}$ от параметра $\eta$ для тех же сочетаний экспериментальных значений $(D, p)$. Цифры у кривых соответствуют зависимостям на рис. 2 .

только решение (25), (26) со знаком „+““:

$$
p_{0}=z^{2}
$$

где

$$
z=\frac{1}{2}(\gamma / \eta)^{1 / 2} D+\sqrt{\frac{\gamma D^{2}}{4 \eta}-p} .
$$

Из рис. 3 видно, что на верхних ветвях кривых повышение температуры частиц за счет взаимного трения в волне уплотнения может достигать больших значений, сопоставимых с температурой воспламенения реальных порошков. Согласно данным экспериментов [8-13], механоактивация приводит к существенному снижению температуры воспламенения порошковых смесей. Так, если воспламенение обычной смеси $\mathrm{Al} / \mathrm{MoO}_{3}$ происходит при температуре свыше $600^{\circ} \mathrm{C}$ (близкой к точке плавления $\mathrm{Al}$ ), то воспламенение механоактивированной смеси $\mathrm{Al} / \mathrm{MoO}_{3}$ происходит на воздухе в виде вспышки при соприкосновении с нагретой поверхностью при температуре от 240 до $300^{\circ} \mathrm{C}$ (в зависимости от типа частиц $\mathrm{Al}$ и дозы активации). С учетом этого, данные рис. 3 объясняют, почему одна и та же порошковая смесь после механоактивации оказывается способной к детонации, в то время как без механоактивации наблюдается только ее горение без перехода в детонацию.

Как следует из (24), характерная скорость детонации $D_{0}$ является монотонно возрастающей функцией $\Delta T_{i g n}$. При механоактивации порошка происходит снижение температуры воспламенения частиц, а значит и снижение характерной скорости детонации $D_{0}$. Вместе с тем, согласно данным [8-13], в результате механоактивации скорость детонации возрастает. В соответствии с (20) скорость детонации растет с ростом давления за фронтом детонации, поэтому, видимо, рост давления в продуктах детонации, вызванный механоактивацией, „перекрывает“ связанное с механоактивацией падение $D_{0}$ : механоактивация порошка повышает его химическую активность (как за счет увеличения удельной поверхности контакта реагентов, так и за счет дефектов кристаллической структуры окислителя), что приводит к увеличению массовой скорости горения частиц в расчете на единицу их массы, что, в свою очередь, приводит к росту давления за фронтом детонации.

Соотношение (13) позволяет объяснить, почему в плотных порошках детонация по рассматриваемому механизму невозможна. При заданной температуре воспламенения частиц порошка из соотношения (13) можно найти минимальную степень уплотнения порошка в волне уплотнения, при которой эта температура достигается

$$
\left(\frac{\rho_{0}}{\rho_{i g n}}\right)_{\max }=1-\frac{1}{D}\left(\frac{2 c_{p} \Delta T_{i g n}}{\beta}\right)^{1 / 2} .
$$

Принимая, что в волне уплотнения относительная плотность порошка достигает значений $\rho_{i g n}<\rho_{\max } \approx 0.5$, найдем максимальную начальную плотность порошка, при которой возможна детонация низкоплотной порошковой смеси:

$$
\rho_{0 \max }=\rho_{\max }\left[1-\frac{1}{D}\left(\frac{2 c_{p} \Delta T_{i g n}}{\beta}\right)^{1 / 2}\right] .
$$

При начальной плотности порошка $\rho_{0}>\rho_{0 \max }$ детонация невозможна. Здесь скорость $D$ равна либо скорости детонации, либо скорости волны уплотнения, созданной начальным (инициирующим) импульсом. Например, при $\quad D=1500 \mathrm{~m} / \mathrm{s}, \quad c_{p}=0.8 \mathrm{~kJ} /(\mathrm{kg} \cdot \mathrm{K}), \Delta T_{i g n}=250^{\circ} \mathrm{C}$, $\rho_{\max } \approx 0.5$ и $\beta=2$, получим $\rho_{0 \max }=0.35$, что согласуется с данными экспериментов [8-13].

\section{Заключение}

Процесс быстрого распространения химической реакции в низкоплотных механоактивированных порошковых смесях, экспериментально исследованный в работах [8-13], обладает всеми признаками детонации и должен быть признан разновидностью детонации: за счет высокого давления промежуточных газообразных продуктов сгорания частиц происходит резкое уплотнение порошка; зона уплотнения движется в пространстве со скоростью, превышающей скорость звука в исходном порошке; при быстром сжатии порошка в волне уплотнения происходит перегруппировка частиц порошка за счет их взаимного перемещения без заметной деформации частиц, сопровождающаяся интенсивным трением контактирующих частиц; в результате трения отдельные частицы могут нагреваться до высоких температур, при которых происходит их воспламенение на контактной поверхности реагентов (тепловой взрыв) и последующее интенсивное горение; образование высокотемпературных газообразных продуктов сгорания в результате быстрого горения частиц порошка поддерживает высокое давление за фронтом уплотнения, компенсируя 
падение давления за счет истечения газа в окружающую среду, что обеспечивает непрерывное распространение детонационной волны по порошку.

Принципиальным отличием детонационной волны в низкоплотных порошковых смесях от детонационной волны в газах, жидкостях и сплошных твердых взрывчатых веществах является механизм инициирования химических реакций в волне уплотнения: повышение температуры среды, необходимое для инициирования и ускорения химических реакций при классической детонации происходит за счет адиабатического сжатия среды в ударной волне, в то время как в низкоплотных порошках оно происходит за счет трения между частицами в процессе их взаимного перемещения в волне уплотнения.

Как показано выше, детонация в низкоплотных механоактивированных порошковых смесях может быть реализована только в очень узком диапазоне управляющих параметров: начальной плотности порошковой смеси и химической активности частиц порошка. Химическая активность порошка, как комплексный критерий, включает в себя температуру воспламенения частиц порошка и скорость образования промежуточных газофазных продуктов горения порошка (массу газа, выделяющегося за единицу времени в расчете на единицу массы порошка). Она может быть увеличена за счет применения нанопорошков, а также за счет предварительной механоактивации порошка.

\section{Список литературы}

[1] Харитон Ю.Б. В сб.: Вопросы теории взрывчатых веществ / М.-Л.: Изд-во АН СССР, 1947. Книга первая. С. 729.

[2] Raizer Yu.P. Laser-Induced Discharge Phenomena, Consultants Bureau. NY., London, 1977. 366 p.

[3] Boslough M.B. // J. Chem. Phys. 1990. Vol. 92. N 3. P. 1839 1848.

[4] Bennett L.S., Horie Y. // Shock Waves. 1994. Vol. 4. N 3. P. 127-136.

[5] Гордополов Ю.А., Тробимов В.С., Мержсанов А.Г. // ДАН. 1995. T. 341. № 3. C. 327-329.

[6] Болховитинов Л.Г., Бацанов С.С. // ФГВ. 2007. Т. 43. № 2. C. $108-110$

[7] Jette F.X., Higgins A.J. In: Shock Compression of Condensed Matter-2007 / Eds M. Elert, M.D. Furnish, R. Chau, N. Holmes, J. Nguyen. AIP Conf. Proc. 2007. Vol. 955. P. $385-388$.

[8] Долгобородов А.Ю., Махов М.Н., Стрелецкий А.Н., Колбанёв И.В., Гогуля М.Ф., Фортов В.Е. // Химическая физика. 2004. Т. 23. № 9. С. 85-88.

[9] Долгобородов А.Ю., Махов М.Н., Колбанёв И.В., Стрелецкий А.Н., Фортов В.Е. // Письма в ЖЭТФ. 2005. Т. 81. № 7. C. $395-398$.

[10] Dolgoborodov A.Yu., Makhov M.N., Kolbanev I.V., Streletskii A.N., Fortov V.E. // Proc. Thirteenth International Detonation Symposium, July 23-28, 2006. Norfolk, Virginia. ONR 351-07-01. P. 137-144.
[11] Долгобородов А.Ю., Стрелецкий А.Н., Махов М.Н., Колбанёв И.В., Фортов В.Е. // Хим. физика. 2007. Т. 26. № 12. C. $40-45$.

[12] Dolgoborodov A.Yu., Streletskii A.N., Kolbanev I.V., Makhov M.N. // Thirty-Fifth Intern. Pyrotechnics Seminar / Ed. by F.J. Schelling. Fort Collins, Colorado, July 13-18, 2008. P. $169-173$.

[13] Долгобородов А.Ю., Стрелецкий А.Н., Махов М.Н., Теселкин В.А., Гусейнов Ш.Л., Стороженко П.А., Фортов В.E. // Хим. физика. 2012. Т. 31. № 8. С. 1-8.

[14] Gómez L.R., Turner A.M., van Hecke M., Vitelli V. // Phys. Rev. Lett. 2012. Vol. 108. N 5. P. 058001.

[15] van den Wildenberg S., van Loo R., van Hecke M. // Phys. Rev. Lett. 2013. Vol. 111. N 21. P. 218003.

[16] Рашковский С.А., Долгобородов А.Ю. В сб.: Горение и взрыв / Под ред. С.М. Фролова. М.: ТОРУС ПРЕСС, 2014. Вып. 7. С. 309-313.

[17] Rashkovskiy S.A., Dolgoborodov A.Y. // Combustion Sci. Technol. 2017. Vol. 189. N 12. P. 2220-2241.

[18] Рашковский С.А., Долгобородов А.Ю. // Письма в ЖТФ. 2015. Т. 41. Вып. 12. С. 24-31.

[19] Leuenberger H. // Intern. J. Pharmaceutics. 1982. Vol. 12. N 1. P. 41-55. 